\title{
Online Experimentation @FEUP: Five Years of Evaluations
}

\author{
Diana Urbano, Maria de Fátima Chouzal, Maria Teresa Restivo \\ LAETA-INEGI, Faculty of Engineering, University of Porto, Porto, Portugal \\ http://remotelab.fe.up.pt \\ urbano@fe.up.pt, fchouzal@fe.up.pt, trestivo@fe.up.pt
}

\begin{abstract}
The Online Experimentation @FEUP lab gathers a set of experimental resources based on Augmented Reality, Virtual Reality and Haptic Systems. The design, development and implementation of those resources are guided by the following main goals: familiarizing students with the referred technologies, complement hands-on experimentation, motivate students and promote knowledge gain. A brief presentation of the online experimental activities most utilized and evaluated in the past five years in context of different undergraduate courses and at the K12 level is presented. In all the studies conducted, the strategies adopted involve pre- and post-testing to assess knowledge gain, experimental group activities, and individual response to surveys to assess student reaction. The results published in journals, conferences proceedings and book chapters are discussed.
\end{abstract}

Keywords: augmented reality; virtual reality; haptic systems; experimentation; engineering education; conceptual knowledge gain.

\section{Introduction}

For the past three decades, remote experimentation (RE) [1-3] where simulation, data collection and analysis are assisted by instrumentation and computers, has been increasingly used. More recently, Virtual Reality (VR), Augmented Reality (AR) and haptic interactions, are being incorporated in collaborative platforms. Together with RE they constitute what is called Online Experimentation (OE) [4].

Although one should not look at $\mathrm{OE}$ as a replacement of hands-on experimentation, there are certain characteristics of $\mathrm{OE}$ that can enhance learning. The phenomena and concepts involved in most engineering areas are complex, described by intricate mathematical relationships, requiring most of the times high level of abstraction skills that can take a long time to acquire. These difficulties can result in lack of motivation, frustration and undesirable knowledge gaps.

The advantages of using the referred technologies in education are manifold. On one hand VR and AR allow for the visualization of abstract concepts and complex spatial relationships and, in the case of haptic interaction systems, they involve the sense of touch through tactile feedback. Moreover, they make it possible to test the theoretical limits of the physical models, something not often feasible in real experiments. In addition, the virtual nature of the technologies is very suited for exploring dangerous environments and destructive tasks. On top of that, these different ways of exploring the senses contribute to enhance engagement and interactivity, thus having a positive impact on student motivation to learn and on academic performance [5-12].

Other advantage includes suitability for e-learning and b-learning, and flexibility to provide additional time to perform the experiments. However, using OE in Engineering Education (EE) is not only driven by those advantages. AR, VR and haptic systems play an increasingly important role in many of areas of engineering expertise. Industries like the automotive, aircraft, and manufacturing, among others, are using such technologies for many purposes like for instance training, maintenance, assembly and repair. Therefore, it is pertinent that students get in contact with such technologies while learning.

Furthermore, the current pandemic situation has stressed the need to have available diverse online experimental resources in order to avoid in the future possible lack of experimental training in science and engineering education.

The Online Experimentation@FEUP (OE@FEUP) project (https://remotelab.fe.up.pt/) is active since 2003 and is a repository of 42 multidisciplinary online open experimental resources. They are based on the use of different technologies in remote sensing, monitoring and actuation, virtual simulators, virtual/augmented reality and sensorial devices like haptic interfaces, data gloves, 3D glasses, among others.

In this paper, a brief presentation of the available resources is given, with a description of the target populations that used them, publications in journals and conference proceedings, and summarize the conclusions from studies conducted to evaluate their potential as promoters of motivation and conceptual knowledge gain.

\section{Description and methodologies of $\mathrm{OE}$ implementation}

\subsection{Resources at OE@FEUP}

OE@FEUP integrates experiments based on six main types of technologies, or associations: Remote Experiments (RE) (15), Augmented Reality Experiments (ARE) (8), Virtual Experiments with Haptic Interaction (VE\&Haptics) (7), Virtual Reality (VR) (3), Simulators (4) and Instrumented Devices (OID) (5), that are represented in percentage in Figure 1.

In this report, the focus is on the ARE, VE\&Haptics and VR resources that have been extensively used over the past five years in the context of undergraduate engineering programs and K12 level non formal learning. They cover areas from physics, civil, electrical, mechanical and environmental engineering. 


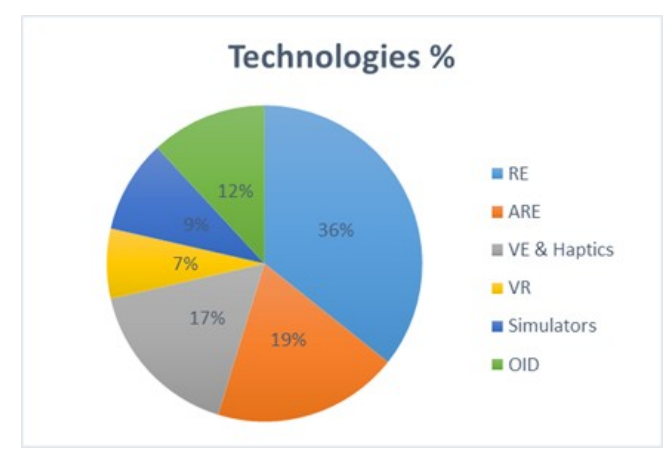

Figure 1. OE@FEUP for all technologies.

The experimental tools offered were designed, developed and implemented with the following main objectives:

- to facilitate the understanding of basic science and engineering concepts;

- to engage and motivate students to learn

- to complement hands-on experimentation

- to be accessible for everyone, everywhere, anytime

- to familiarize engineering students with technologies that they might encounter in their professional future.

Table 1 presents the most used online resources in the past five years available in the OE@FEUP platform.

It shows the type technology, the name of the experimental resource, the context in which they were used and the number of students that had the opportunity to engage in experimental activities with them. The publications containing the description of the resources and of the conducted studies to evaluate them as promoters of motivation and knowledge gain are also depicted. Not all of the studies involve the number of students reported in the table and that corresponds to those who worked in the lab with the OE resource. The experimental activities took place in the framework of several undergraduate courses of different integrated master engineering programs and in the context of the Junior University program of the Porto University [13]. This program brings every years K12 students to the university for different non formal learning activities.

\subsection{Strategies used to evaluate the OE resources}

For the past five years, the OE resources have been evaluated as promoters of motivation and conceptual knowledge gain. These evaluations are linked to the objectives referred above that guide the design, development and implementation of the OE tools.

To evaluate how using the OE influences conceptual knowledge, pre and posttesting is implemented and measures such as normalized gain and Cohen's $d$ effect size are calculated to provide a quantitative estimate of knowledge gain (see [17] and references therein).
Table 1. Online experimentation technologies, resources, target population, number of students and references.

\begin{tabular}{|c|c|c|c|c|}
\hline Technology & $\begin{array}{l}\text { Name of the } \\
\text { Resource }\end{array}$ & $\begin{array}{c}\text { Target } \\
\text { Population }\end{array}$ & $\begin{array}{l}\text { Approx. } \\
\text { number } \\
\text { of } \\
\text { students }\end{array}$ & References \\
\hline \multirow{3}{*}{ ARE } & $\begin{array}{c}\text { "AR DC circuit } \\
\text { puzzle" }\end{array}$ & $\begin{array}{l}\text { ME,CE, } \\
\text { IEM,K12 }\end{array}$ & 900 & $\begin{array}{l}{[14],[15],} \\
{[16],[17],} \\
{[18],[19]}\end{array}$ \\
\hline & $\begin{array}{c}\text { "AR straightness } \\
\text { evaluation" }\end{array}$ & IEM & 160 & [19] \\
\hline & $\begin{array}{c}\text { "Groundwater } \\
\text { flow on a small } \\
\text { scale } \\
\text { embankment } \\
\text { dam" }\end{array}$ & CE & 170 & [19] \\
\hline \multirow[b]{2}{*}{ VE\&Haptics } & $\begin{array}{l}\text { "Elastic constant } \\
\text { of Coil Springs" }\end{array}$ & EVE, K12 & 170 & [20] \\
\hline & $\begin{array}{l}\text { "Mechanical } \\
\text { Characterization } \\
\text { of Materials" }\end{array}$ & CE (Brazil) & 20 & [21],[22] \\
\hline VR & $\begin{array}{l}\text { "Mechanics 3D } \\
\text { virtual lab" }\end{array}$ & K12 & 80 & [23] \\
\hline
\end{tabular}

ME - Mechanical Engineering, IEM - Industrial and Management Engineering, CE - Civil Engineering, EVE - Environmental Engineering, K12 - High school students

The purpose of the pre- test is to engage students in thinking about the physical phenomena they are about to observe and for possible explanations of the phenomena. Having observed and experimented, they can check whether their prediction is confirmed. This procedure also permits instructors to get a clear idea of the most common misconceptions. The post- test allows for establishing how students changed their view due to experimenting using virtual system environments. The change from incorrect to correct answer may affect memory and on understanding of the underlying concept.

Before the experimental activity, students answer individually to a set of conceptual multiple-choice questions about the most relevant concepts addressed in the experiment. Then, working in groups, they explore the resources. Immediately after that, they answer again individually to the same set of questions. Whenever possible, sometime after the experimental activity, they answer to the same set of questions and to others related to the same concepts, which allows for assessing knowledge retention. Calculation of the normalize gain and of effect size of mean's differences provide measurements of the efficacy of the activity to correct possible prior misconceptions.

To investigate students' reaction to the use of the $\mathrm{OE}$ resources, questionnaires are used. They are based on existing questionnaires in the literature and are intended to measure relevant psychological traits known to be connected with motivation as well as performance [26, 27]. Examples of latent variables considered are selfefficacy in using new technologies, interest, perceived value of $\mathrm{OE}$ in the context of engineering training, ease 
of use of the resources, attitude towards using OE and behavioral intention to use the technologies in the future [27]. Analysis of the surveys include descriptive statistics and, for large enough samples, multivariate techniques such as regression analysis and structural equation models are applied. They allow for investigating the influence that the psychological traits described have on each other.

\section{Discussion}

The evaluation of the resources is performed over the years using the same methodology involving different students. The results of the several studies reported in the references shown in Table 1 are very consistent. They indicate that the OE learning tools have a good impact on conceptual knowledge gain and that students view them as interesting, valuable for the learning process, easy to use, and their attitude towards using OE to learn is very positive.

Although no direct evidence emerges from the studies, they suggest that associating OE with the preand post- testing might condition the affective and cognitive response of the students. Students interact with the resources guided by the questions they are trying to answer. They have the goal of observing certain phenomena and to understand the concepts addressed in the questions. This might influence their interest and their perception of the utility of the $\mathrm{OE}$ tools to learn.

The fact that large number of students from different engineering programs and from K12 level respond similarly in different years, indicates the relevance of exposing them to such tools.

Moreover, the results also indicate that the resources proved to offer a good instructional design, fulfilling the goals behind their conception.

Other important conclusion taken from the studies performed is that there are no significant gender differences, both in students' reaction and in knowledge gain.

The results encourage the authors to continue using the $\mathrm{OE}$ resources in their teaching practices as they have shown a consistent potential to promote student engagement and conceptual knowledge gain.

\section{References}

[1] Alam, F; Hadgraft, R. G.; Subic, A. (2014) Technologyenhanced laboratory experiments in learning and teaching. In: Using Technology Tools to Innovate Assessment, Reporting, and Teaching Practices in Engineering Education, p. 289-302. http://hdl.handle.net/10453/119833

[2] Barrios, A. et al. (2013) A multi-user remote academic laboratory system. Computers \& Education 62(C): 111122. DOI: $10.5555 / 2753873.2753922$

[3] Jong, T.; Linn, M. C.; Zacharia, Z. C. (2013) Physical and Virtual Laboratories in Science and Engineering Education. Science 340(6130): 305-308. DOI: 10.1126/science.1230579

[4] Restivo, M.T.; Cardoso, A. (2013) Exploring Online Experimentation. Int. Journal of Online and Biomedical Engineering 9: 4-6. https://online-journals.org/index.php/ijoe/article/view/3448/0
[5] Wu, H.-K.; Lee, S. W.-Y.; Chang, H.-Y.; Liang, J.-C. (2013) Current status, opportunities and challenges of augmented reality in education. Computers \& Education 62: 41-49. DOI: 10.1016/j.compedu.2012.10.024

[6] Sidhu, M. S. (2019) Evaluation Study Outcome of Augmented Reality Technology for Solving Engineering Problems in UNITEN: Augmented Reality Technology for Solving Engineering Problems in UNITEN. Int. Journal of Information and Communication Technology Education 15(2): 69-84. DOI: 10.4018/Ijicte.2019040105

[7] Jensen, L.; Konradsen, F. (2018) A review of the use of virtual reality head-mounted displays in education and training. Education and Information Technologies 23: 1515-1529. DOI: $10.1007 / \mathrm{s} 10639-017-9676-0$

[8] Nickerson, J. V; Corter, J. E.; Esche, S. K.; Chassapis, C. (2007) A model for evaluating the effectiveness of remote engineering laboratories and simulations in education. Computers \& Education 49(3): 708-725. DOI: 10.1016/j.compedu.2005.11.019

[9] Ogot, M.; Elliott, G.; Glumac, N. (2003) An Assessment of In-Person and Remotely Operated Laboratories. Journal of Engineering Education 92(1): pp. 57-64. doi: 10.1002/j.2168-9830.2003.tb00738.x

[10] Hamza-Lup, F. G.; Baird, W. H. (2012) Feel the Static and Kinetic Friction. In: Haptics: Perception, Devices, Mobility, and Communication, 181-192. DOI: 10.1007/978-3-642-31401-8 17

[11] Minogue, J.; Jones, M. G. (2006) Haptics in Education: Exploring an Untapped Sensory Modality. Review of Educational Research, 76(3): 317-348. DOI: 10.3102/00346543076003317

[12] Williams, R. L.; Chen, M.-Y.; Seaton, J. M. (2003) Haptics-Augmented Simple-Machine Educational Tools. Journal of Science Education and Technology 12(1): 112. DOI: $10.1023 / \mathrm{A}: 1022114409119$

[13] Marques, J. C.; Restivo, M. T. (2012) Working with Young People at University of Porto. IJEP, 2: 23-25. https://online-journals.org/index.php/i-jep/article/view/1 893

[14] Restivo, M. T.; Chouzal, M. F.; Rodrigues, J.; Menezes, P; Patrão, B.; Lopes, J. B. (2014) Augmented Reality in Electrical Fundamentals. Int. J. Online Eng., 10: pp. 6872.

https://www.online-journals.org/index.php/i-joe/index

[15] Menezes, P; Chouzal, M. F.; Urbano, D.; Restivo, M. T. (2017) Augmented Reality in Engineering. Cham: Springer International Publishing, in Interactive Collaborative Learning, 221-228. https://doi.org/10.1007/978-3-319-50340-0 18

[16] Urbano, D.; Chouzal, M. F.; Restivo, M. T. (2020) Evaluating an online augmented reality puzzle for DC circuits: Students' feedback and conceptual knowledge gain. Computer Applications in Engineering Education. DOI: $10.1002 /$ cae.22306

[17] Urbano, D; Chouzal, M. F.; Restivo, M. T. (2015) How Students and Teachers React to an AR free Puzzle Game: preliminary tests. IEEE EDUCON2015 Global Engineering Education Conference, pp. 852-855. DOI: 10.1109/EDUCON.2015.7096072

[18] Urbano, D.; Chouzal, M.F. ; Restivo, M.T (2020) A case study of AR technology and engineering students: Is there a gender gap? In: Proc. 17th International Conference on Remote Engineering and Virtual Instrumentation (REV2020), University of Georgia, Athens, USA. Online: https://www.researchgate.net/publication/340925813 A case study of AR technology and engineering studen ts Is there a gender gap 
[19] Restivo, M. T.; Rodrigues, J; Chouzal, M. F. (2014) Let's Work with AR in DC Circuits. In: Proc. ICL2014 International Conference on Interactive Collaborative Learning, pp. 884-885. DOI: 10.1109/ICL.2014.7017890

[20] Urbano, D.; Chouzal, M. F.; Restivo, M. T. (2015) Feeling the Elastic Force with a Haptic Device A learning experience with $\mathrm{K} 12$ and first year engineering students. In: Proc. 2015 Experiment at Int C, pp. 306309. DOI: $10.1109 /$ Expat.2015.7463285

[21] Urbano, D.; Marques, J. C. ; Chouzal, M. F.; Restivo, M. T.; Andreatta-da-Costa, L. (2016) Experimental training in engineering. In: Proc. IEEE EDUCON2016 Global Engineering Education Conference. pp. 1046-1050. DOI: 10.1109/EDUCON.2016.7474682

[22] Restivo, M. T.; Lopes, A. M. ; Machado, L.; Moraes, R.; Chouzal, M. F. (2014) Feeling Materials' Stiffness by Haptics for Training. Journal of Materials Education 36(3-4):51-67.Online:

https://www.researchgate.net/publication/266331392 Fe eling Materials Stiffness by Haptics for Training

[23] Restivo, M. T.; Urbano, D.; Chouzal, M.F. (2015) Hi kids: That's funny! Mechanics 3D Virtual lab. In: Proc. International Conference on Interactive Mobile Communication Technologies and Learning (IMCL2015), $\quad$ p. $232-235 . \quad$ DOI: 10.1109/IMCTL.2015.7359593
[24] Hake， R. R. (1998) Interactive-engagement versus traditional methods: A six-thousand-student survey of mechanics test data for introductory physics courses. American Journal on Physics 66(1): 64-74.

[25] J. Cohen (1977). Statistical power analysis for the behavioral sciences, Academic Press, New York, NY.

[26] Pintrich, P. R.; De Groot, E. V. (1990) Motivational and selfregulated learning components of classroom academic performance. Journal of Educational Psychology 82(1): 33-40. DOI: $10.1037 / 0022-$ 0663.82.1.33

[27] Park, S. Y. (2009) An analysis of the technology acceptance model in understanding university students' behavioral intention to use e-learning. Educational Technology \& Society 12(3): 150-162. http://www.jstor.org/stable/jeductechsoci.12.3.150 